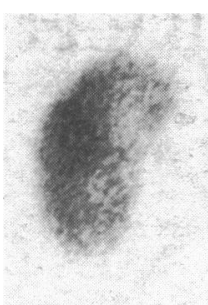

(a)

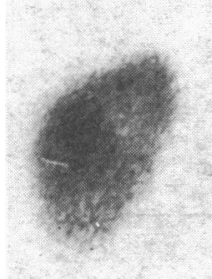

(c)

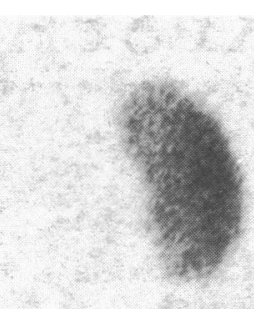

(b)

\section{b)}

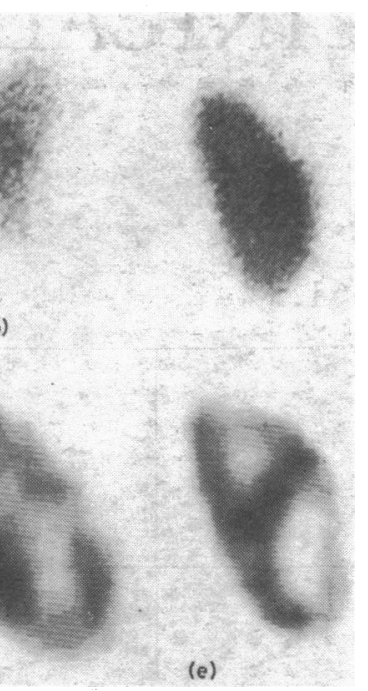

(e)

FIG 2-Conventional gamma-camera images: (a) posterior, $(b)$ right posterio oblique, and (c) left posterior oblique; and sagittal sections through $(d)$ right and $(e)$ left kidney, which clearly show hypertrophied column of Bertin.

further radioactive substance being given, emission computed tomography of the kidneys was then performed using the same gamma camera connected to an image analysis computer (Gamma-11, Digital Equipment $\mathrm{Co}$ ) in its rotation mode. Data were collected for $20 \mathrm{~s}$ at each of 64 views equally spaced through $360^{\circ}$ around the patient. Sagittal sections were then computed (fig $2 d, e$ ), which clearly showed that in the left kidney the functioning cortical tissue extended across the middle of the kidney. The radiographs were then reviewed and another ultrasound investigation done, after which it was concluded that the left kidney showed partial reduplication of the collecting system with interposed solid tissue having the characteristics of normal renal parenchyma. The renal abnormality was therefore a hypertrophied column of Bertin.

\section{Discussion}

The column of Bertin may be a source of considerable confusion in radiographic investigation of the kidney since it may simulate a renal tumour on an excretion urogram and may require angiography for diagnosis. ${ }^{4}$ Ultrasonography may be unhelpful, not only if the patient yields poor-quality images owing to, for example, obesity but also because the calyceal appearance in healthy kidneys varies considerably and a small amount of distortion is therefore easily missed. Conventional radionuclide images may also, as in this case, be unhelpful. The usual procedure to determine the nature of the suspected lesion would then be to proceed to selective renal angiography. ${ }^{4}$ In this case the necessity for this invasive investigation of a healthy kidney was obviated by the clear tomographic radionuclide images obtained. In other patients we have found that emission tomographic imaging of the kidney can be a useful adjunct to other non-invasive studies. ${ }^{5}$

We are grateful to Dr P G Rose, consultant radiologist, for his advice and opinion on this case.

\section{References}

1 Ell PJ, Deacon JM, Ducasson D, Brendel A. Emission and transmission brain tomography. Br Med 7 1980;280:438-40.

2 Khan O, Ell PJ, Jarrit PH, Cullum ID, Williams ES. Comparison between emission and transmission computed tomography of the liver. Br Med F 1981 ;283:1212-4.

3 Larsson SA. Gamma camera emission tomography. Acta Radiol [Suppl] $1980 ; 363: 1-75$.

4 Witten DM, Myers GH, Utz DC, eds. Tumours of the genitourinary tract. Emmett's clinical urography. 4th ed. Philadelphia: W B Saunders, 1977 1493.

5 Williams ED, Parker C, Roy RR, Rankin D, Holland A, Brown M Multiple section emission computed tomography of the kidney: an assessment. In: Joekes AM, Constable AR, Brown NJG, Tauxe WN, eds. Radionuclides in nephrology. London: Academic Press, 1982:71-5.

\title{
Cryptic stage of sleeping-sickness trypanosome developing in choroid plexus epithelial cells
}

\author{
M O ABOLARIN, D A EVANS, D G TOVEY, W E ORMEROD
}

\begin{abstract}
Electronmicrographs of the choroid plexus from rats infected with Trypanosoma brucei rhodesiense showed that trypomastigotes from the perivascular spaces may penetrate and undergo multiple division in the ependymal cells which locally constitute the blood-brain barrier. Progressive degeneration of the ependymal cell liberates trypomastigotes back into the perivascular space, from which re-entry into the blood may occur. Re-entry to the blood does not take place from any tissues other than the brain and its membranes.
\end{abstract}

\footnotetext{
London School of Hygiene and Tropical Medicine, London WC1E 7HT

M O ABOLARIN, PHD, principal lecturer, Kwara State College, Nigeria D A EVANS, PHD, senior lecturer

D G TOVEY, DIPEM, senior medical laboratory scientific officer

W E ORMEROD, DM, DSC, senior lecturer
}

These findings suggest that the ependymal cells of the choroid plexus are the site of the cryptic stage of the sleeping-sickness trypanosome.

\section{Introduction}

African sleeping sickness is regarded as one of the most enigmatic of diseases because of its tendency to relapse after apparently successful treatment with chemotherapy. Similarly, when spontaneous remission occurs parasitaemia may be re-established months or even years after the initial infection. This occurs particularly with the Gambian form. Such behaviour suggests the existence of a cryptic stage somewhere in the tissues from which relapses may be generated. Such a cryptic stage occurs in Plasmodium vivax malaria. Hitherto, however, only indirect evidence of a cryptic stage has been documented, and one study suggested the choroid plexus as a site where cryptic forms of the sleeping-sickness parasite might be expected to develop. ${ }^{1}$

Recent work on the relapse of Trypanosoma brucei infections 
in rodents indicated that during remission a site of infection remains in the region of the brain. ${ }^{23}$ Such remissions induced by treatment with salicylhydroxamic acid in combination with glycerol and associated with complete removal of parasites from the blood are invariably followed by relapse parasitaemias, presumably due to reinvasion of the blood by trypomastigotes from extravascular sites. ${ }^{4}$

We present direct evidence for the existence of a cryptic stage of the sleeping-sickness trypanosome developing in the epithelium (ependymal cells) covering the choroid plexus.

\section{Materials and methods}

Two strains of $T$ brucei were used: $T$ brucei brucei (TREU 667), a strain derived from an animal but of uncertain origin and known to produce a chronic infection in mice, ${ }^{3}$ and $T$ brucei rhodesiense (LSHTM 180), isolated from man in Botswana and passaged seven times. Both strains were preserved by freezing below $-80^{\circ} \mathrm{C}$. All inoculations were made in phosphate buffer ( $\mathrm{pH} 7.4$ ) with $1 \%$ dextrose added.

Donor mice inoculated with TREU 667 were allowed to develop infection for three, 10 , or 21 days and then treated with salicyl- hydroxamic acid $500 \mathrm{mg} / \mathrm{kg}$ and glycerol $4 \mathrm{~g} / \mathrm{kg}$ (see table I). Once the blood was shown to be clear of trypanosomes (DEAE cellulose concentration method ${ }^{6}$ ) clean mice were inoculated with donor tissue, in some cases blood, in others brain homogenate. Table I shows the numbers of clean mice that became infected together with the first days of patent parasitaemia after inoculation.

In other experiments one mouse was injected with TREU 667 and another with LSHTM 180. Salicylhydroxamic acid and glycerol were given as before and clearance of parasites from the blood verified in the

TABLE I-Persistence of cryptic forms of sleeping-sickness parasite in mouse brain*

\begin{tabular}{cccc}
\hline & & \multicolumn{2}{c}{$\begin{array}{c}\text { No of clean mice parasitaemic/total } \\
\text { inoculated (first day of parasitaemia) }\end{array}$} \\
\cline { 2 - 4 } $\begin{array}{c}\text { Day of treatment of } \\
\text { donor mice after } \\
\text { infection }\end{array}$ & No of donor mice & $\begin{array}{c}\text { Mice inoculated } \\
\text { with blood }\end{array}$ & $\begin{array}{c}\text { Mice inoculated } \\
\text { with brain }\end{array}$ \\
\hline 3 & 7 & $0 / 12$ & $1 / 12(11)$ \\
10 & 8 & $1 / 11(16)$ & $11 / 11(5-15)$ \\
21 & 8 & $1 / 11(10)$ & $10 / 11(5-12)$ \\
\hline
\end{tabular}

* Donor mice infected with TREU 667 treated with salicylhydroxamic acid and glycerol on day stated. Clean mice then inoculated with donor blood or brain 10 days.

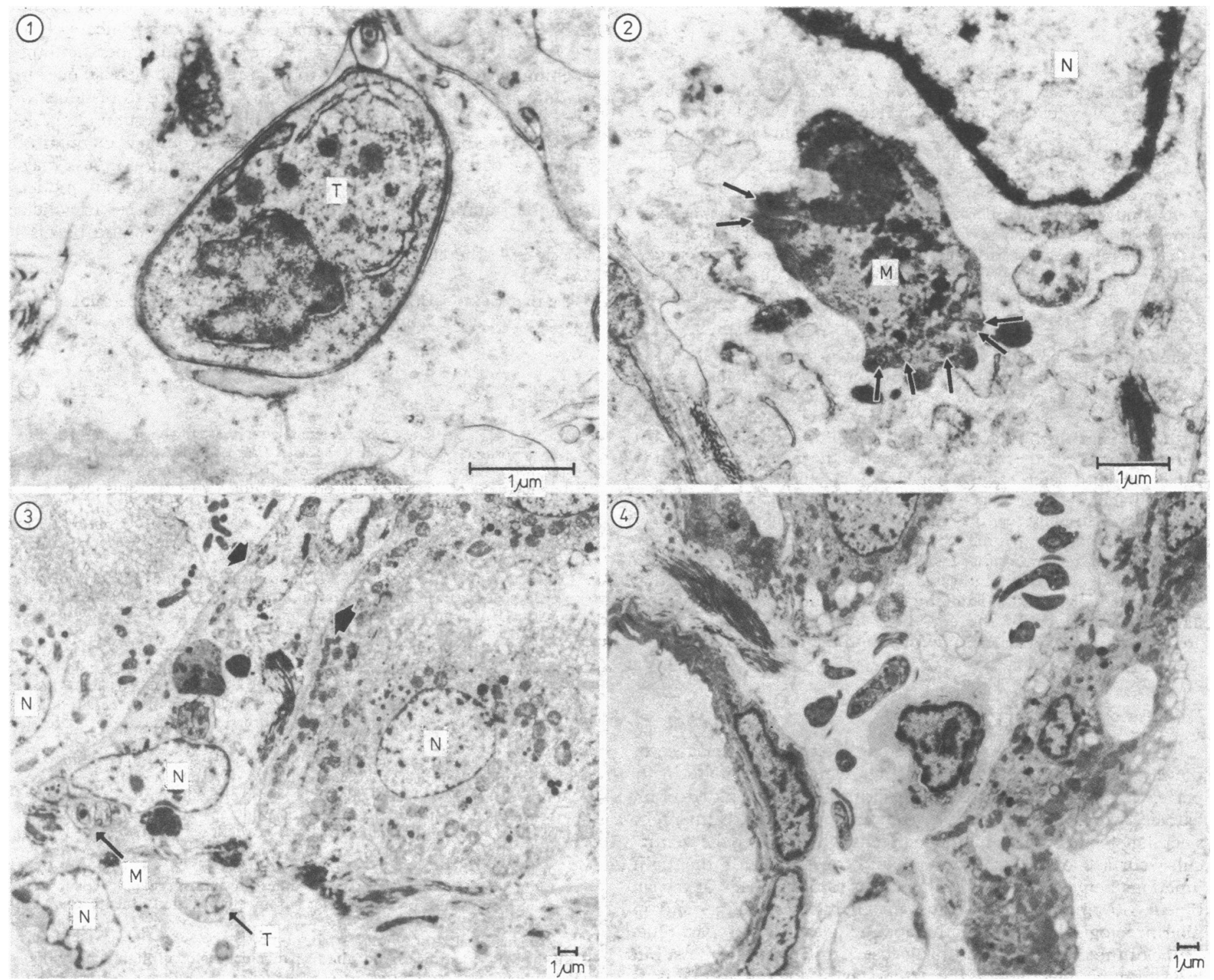

Fig 1-Trypomastigote $(T)$ in intact ependymal cell. FIG 2-Multiple-division form $(\mathbf{M})$ in intact ependymal cell $(\mathbf{N}=$ nucleus of ependymal cell) from rat treated with salicylhydroxamic acid and glycerol. Flagellar profiles arrowed. FIG 3-Multiple-division form (M) and trypomastigotes (T) in degenerating ependymal cell $(\mathrm{N}=$ nucleus of ependymal cell). Limiting membranes of adjoining cells arrowed. FIG 4-Liberation of trypomastigotes after destruction of ependymal host cell. 
same way. The mice were killed on day 13 and their organs homogenised and injected into clean mice (see table II). Groups of five mice were injected with extract from each homogenised organ and the experiment repeated twice.

TABLE II-Distribution of persistent forms of sleeping-sickness parasite in tissue. Figures are first days of parasitaemia after injection of donor tissue*

\begin{tabular}{lllllllllll}
\hline & \multicolumn{8}{c}{ Donor tissue injected into clean mice } \\
\cline { 2 - 9 } $\begin{array}{l}\text { Donor } \\
\text { infection }\end{array}$ & Siver & Spleen & Brain Lung Kidney & Ovary Eye & $\begin{array}{l}\text { Skeletal } \\
\text { muscle }\end{array}$ & $\begin{array}{c}\text { Heart Blood } \\
\text { muscle }\end{array}$ \\
\hline TREU 667 & 0 & 0 & 5,6 & 0 & 0 & 0 & 0 & 0 & $\overline{0}$ & 0 \\
LSHTM 180 & 0 & 0 & 5 & - & 0 & - & - & - & 0 & 0
\end{tabular}

* $0=$ No parasitaemia. $-=$ Not injected. Homogenised organs from two infected donor mice treated with salicylhydroxamic acid and glycerol injected into groups of five clean mice. Only mice injected with brain became parasitaemic.

Four rats were killed with ether 24-27 days after inoculation with LSHTM 180 and their brains dissected. One had been treated with salicylhydroxamic acid and glycerol, with the clearance of parasites from the blood verified as above. Choroid plexuses of the lateral ventricle were fixed in situ with $5 \%$ glutaraldehyde, extracted, and post-fixed with $1 \%$ osmium tetroxide. Microsections were cut from Araldite and examined in an AEI 801 electron microscope.

\section{Results}

The inoculation experiments showed that when the blood had been cleared by salicylhydroxamic acid and glycerol cryptic forms of the sleeping-sickness trypanosome persisted in the brain but in no other organ (tables I, II). These results generally confirmed those of other workers ${ }^{2}{ }^{3}$ and formed a background to our further study of the actual location of the cryptic forms.

Our study by electron microscopy showed numerous trypomastigote forms in the perivascular region of the choroid plexus and disappearance of the perivascular forms after treatment with salicylhydroxamic acid and glycerol. We also, however, detected small numbers of intracellular forms located in the epithelial (ependymal) cells of the choroid plexus; these were not affected by treatment (see fig 2).

Figures 1 to 4 show a series of changes which intracellular development of the trypomastigote appears to have brought about in the ependymal cell. In figure 1 an apparently undivided trypomastigote is at least partially surrounded by the walls of a parasitophorous vacuole; this feature may represent an early stage in intracellular development of the trypanosome. ${ }^{7}$ Figure 2 shows a multiple-division stage; in neither instance did the ependymal cell show the massive degeneration associated with later stages, nor were secretory filaments seen. ${ }^{8}$ Figure 3 shows a later stage of multiple division which differs from binary fission usually seen in trypomastigotes dividing in the blood, though the nucleus of the ependymal cell has remained intact, considerable degeneration has taken place which has caused the cell to collapse: this collapse is indicated by the closeness of the limiting membranes (arrowed) of adjoining cells. Figure 4 shows the final stage of destruction of the ependymal cell and liberation of the products of the trypanosome's division into the perivascular space.

\section{Discussion}

The choroid plexus is of particular interest both because of the large numbers of trypomastigotes which accumulate in its perivascular spaces ${ }^{9}$ and because it forms part of the blood-brain barrier, which is of particular relevance in the treatment of sleeping sickness. The ependymal cells which cover the ventricular surface of the choroid plexus, together with the tight junctions between them, form a barrier to the passage of trypan blue. ${ }^{10}$ Suramin, which is close in chemical structure and in pharmacological and chemotherapeutic activity to trypan blue, is one of the most important drugs used in sleeping sickness, but it is often ineffective in the later stages. Presumably this is because it cannot reach trypanosomes that have crossed the blood-brain barrier or have entered some other closed site. If the ependymal cells were invaded by the trypanosome these cells might act as such a closed site and protect the trypanosome not only against drugs but also against other large molecules ${ }^{11}$ of the host's protective mechanisms.

Alternatively, other sites in the brain and its membranes may be available for the development of intracellular forms, and we have evidence (as yet incomplete) that development of intracellular stages may also take place in ependymal cells which line the ventricles.

Our present aim, however, is to present evidence of intracellular development of $T$ brucei in the choroid plexus (which has not hitherto been described) and to relate this finding to the presence of extracellular trypomastigotes in the perivascular region of the choroid plexus. Perivascular trypomastigotes in the choroid plexus are already well known, and Van Mark et al quoted some nine reports of their existence.

Some of these perivascular trypomastigotes entered the space by penetrating the vessel wall, as previous workers have postulated, but others, we consider, entered it when the cells in which they were reproducing had been destroyed.

Intracellular trypomastigotes are not seen as often in the choroid plexus as those that are extracellular. We have examined some 20-30 such forms, and because of partial or total destruction of the host cell it has not always been easy to decide whether they were intracellular or not. Now that we recognise the existence of intracellular trypomastigotes in the choroid plexus, however, we have little difficulty in finding them by transmission electron microscopy in ependymal cells of rats and mice.

We believe that our finding is important in understanding sleeping sickness, particularly in relation to the persistence of the infecting organism in the brain and its failure to respond to chemotherapy if this has been delayed beyond a certain interval. Invasion of the cerebrospinal fluid and secondary meningitis which we have observed in experimental sleeping sickness may occur via the choroid plexus; and this may act as a useful model for understanding other meningoencephalitic diseases in which the pathogen may also develop in ependymal cells and be distributed via the choroid plexus.

We thank C A J Brightman and Senait Assefa for determining the infectivity of tissue homogenates.

\section{References}

1 Ormerod WE, Venkatesan S. An amastigote phase of the sleeping sickness trypanosome. Trans $R$ Soc Trop Med Hyg 1971;65:736-41.

2 Seed JR, Effron HG. Simultaneous presence of different antigenic populations of Trypanosoma brucei gambiense in Microtus montanus. Parasitology 1973;66:269-78.

3 Jennings FW, Whitlaw DD, Holmes PH, Chizyuka HGB, Urquhart GM. The brain as a source of relapsing Trypanosoma brucei infection in mice after chemotherapy. Int $\mathcal{7}$ Parasitol 1979;9:381-4.

${ }^{4}$ Evans DA, Brightman CAJ. Pleomorphism and the problem of recrudescent parasitaemia following treatment with salicylhydroxamic acid (SHAM) in African trypanosomiasis. Trans $R$ Soc Trop Med Hyg $1980 ; 74: 601-4$

${ }^{5}$ Clarkson A, Brohn F. Trypanosomiasis: an approach to chemotherapy by the inhibition of carbohydrate metabolism. Science 1976;194:204-6.

${ }^{6}$ Lumsden WHR, Kimber CD, Evans DA, Doig SJ. Trypanosoma brucei miniature anion-exchange centrifugation technique for detection of low parasitaemias: an adaptation for field use. Trans $R$ Soc Trop Med Hyg $1979 ; 73: 312-7$

Evans DA, Ellis DS. Penetration of mid-gut cells of Glossina morsitans by Trypanosoma brucei rhodesiense. Nature 1975;258:231-3.

${ }^{8}$ Ellis DS, Ormerod WE, Lumsden WHR. Filaments of Trypanosoma brucei: some notes on differences in origin and structure in two strain of Trypanosoma (Trypanozoon) brucei rhodesiense. Acta Trop (Basel) $1976 ; 33: 152-65$.

9 Van Mark EAE, Le Ray D, Beckers A, Jacob W, Wery M, Gigase PLJ Light and electron microscope studies on extravascular Trypanosoma brucei gambiense in the brain of chronically infected rodents. Ann Soc Belg Med Trop $1981 ; 61: 57-78$.

10 Goldman EE (1910). Quoted by Bradbury. ${ }^{12}$

11 Rifkin MR. Identification of the trypanocidal factor in high density lipoprotein. Proc Natl Acad Sci USA 1978;75:3450-4.

12 Bradbury M. The concept of a blood brain barrier. Chichester: Wiley and Sons, 1979:38.

(Accepted 24 August 1982) 